\title{
铜催化的二氟卡宾对氨基酸的不对称二氟甲基化
}

\author{
林锦鸿 $a, b \quad$ 肖吉昌*, $a$ \\ $\left({ }^{a}\right.$ 中国科学院上海有机化学研究所 有机氟化学重点实验室 中国科学院大学 上海 200032) \\ ( ${ }^{b}$ 上海大学化学系 上海 200444)
}

\section{Cu-Catalyzed Asymmetric Difluoromethylation of Amino Acids with Difluorocarbene}

\author{
Lin, Jinhong ${ }^{a, b} \quad$ Xiao, Jichang ${ }^{*, a}$
}

( ${ }^{a}$ Key Laboratory of Organofluorine Chemistry, Shanghai Institute of Organic Chemistry, University of Chinese Academy of Sciences, Chinese Academy of Sciences, Shanghai 200032)

( ${ }^{b}$ Department of Chemistry, Shanghai University, Shanghai 200444)

二氟甲基 $\left(\mathrm{HCF}_{2}\right)$ 具有较强亲脂性和吸电子效应，可 作为氢键供体, 又能充当羟基和颈基的生物电子等排 体 ${ }^{[1]}$, 因而在药物研发、农药化学和材料化学等领域中 受到广泛关注; 如何向分子中引入二氟甲基成为有机氟 化学的研究热点. 二氟甲基化是一种直接而有效的策 略, 目前已发展出了许多二氟甲基化试剂以及二氟甲基 化方法 ${ }^{[2]}$. 然而, 不对称二氟甲基化少有研究, 仍具有 较大的挑战性.

自从 1960 年 “二氟卡宾(difluorocarbene)” 概念首 次被提出以来 ${ }^{[3]}$, 二氟卡宾化学取得了快速发展. 作为 亲电性的单线态卡宾, 二氟卡宾在有机合成中发挥了重 要作用, 可用于实现许多类型的反应, 如烯烃或炔烃的 $[2+1]$ 环化以及 $\mathrm{X}-\mathrm{H}$ 键 $(\mathrm{X}=\mathrm{C}, \mathrm{N}, \mathrm{O}$ 等)的二氟甲基化 等 ${ }^{[4]}$. 这些反应能够构建不同的含氟基团, 如偕二氟环 丙基和二氟甲基等. 在二氟卡宾对 $\mathrm{X}-\mathrm{H}$ 键的二氟甲基 化中, $\mathrm{C}-\mathrm{H}$ 键的二氟甲基化是一个研究难点, 近年来得 到不少关注 ${ }^{[5-6]}$. 二氟卡宾因活性太高, 在所参与的各种 反应中一般都难以控制立体选择性. 辅基控制的办法能 够实现二氟卡宾对 $\mathrm{C}-\mathrm{H}$ 的非对映选择性二氟甲基化, 但 $d e$ 值偏低(主要为 $60 \%$ 左右) ${ }^{[7]}$; 有机小分子催化的方 法可实现对映选择性二氟甲基化, ee 值中等(60\% $80 \%)^{[8]}$. 最近, 中国科学技术大学化学系郭昌课题组 ${ }^{[9]}$ 报道了 $\mathrm{Cu}$-催化的二氟卡宾对 $\mathrm{C}-\mathrm{H}$ 键的不对称二氟甲 基化, 反应能够取得优秀的对映选择性. 这是首例以二 氟卡宾高效实现的不对称二氟甲基化方法.

他们以廉价易得的工业原料 $\mathrm{HCF}_{2} \mathrm{Cl}$ 为二氟卡宾试
剂, $\mathrm{Cu}$ 配合物为催化剂, 将二氟甲基不对称地引入到亚 胺酯(1 或 4)中, 醛亚胺酯水解之后可得到二氟甲基取代 的手性氨基酸酯(Scheme 1). 亚胺酯的酯 $\alpha$ 位 $\mathrm{C}-\mathrm{H}$ 键具 有一定的酸性，容易在碱作用下脱质子产生碳负离子,

$$
\text { (a) }
$$

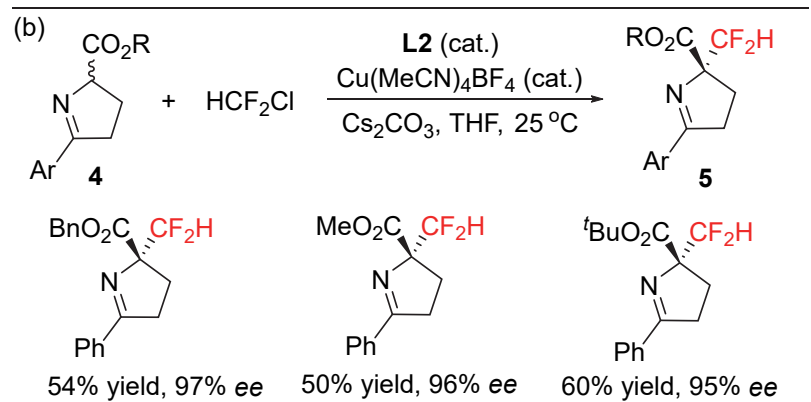

$$
\mathrm{Ph}^{\mathrm{Ph}}
$$

图式 $1 \mathrm{Cu}$-催化的二氟卡宾对亚胺酯的不对称二氟甲基化 Scheme 1 Cu-catalyzed asymmetric difluoromethylation of imine esters

\footnotetext{
* Corresponding author. E-mail: jchxiao@sioc.ac.cn. Published online July 14, 2021.
} 
碳负离子进攻二氟卡宾. 该反应可以实现优秀的对映选 择性二氟甲基化，并且兼容醛亚胺酯和酮亚胺酯，同时 具有较广泛的底物普适性.

$\alpha$-二氟甲基鸟氨酸(7)在非洲昏睡病的治疗中显示 出较好的生物活性, 而这种氨基酸的绝对构型对活性的 影响至关重要. 郭昌课题组采用他们发展的方法, 以互 为对映体的配体来控制手性, 高对映选择性地分别合成 了 $R$-和 $S$-构型的二氟甲基鸟氨酸(Scheme 2), 这为继续 研究这两种异构体的生物活性奠定了基础.

不管底物是何种构型, 反应产率以及 $e e$ 值并无明 显变化(Scheme 3, a); 此外, 对映体纯的底物在碳酸铯 作用下很快就会发生消旋化(10 min). 这说明底物中的
酯 $\alpha$ 位 $\mathrm{C}-\mathrm{H}$ 键在碳酸铯作用下会发生中和反应产生碳 负离子, 碳负离子进攻二氟卡宾时构建手性中心, $\mathrm{Cu}$ 络 合物的手性环境控制进攻过程的立体选择性. 当反应中 有氛代水存在时，会产生 $40 \%$ 的氛代产物(Scheme $3, b$ ), 证明反应经历了二氟卡宾的过程. 若在二氟甲基化反应 中加入自由基捕获剂, 如 2,2,6,6-四甲基哌啶氧化物 (TEMPO)或 2,6-二叔丁基对甲酚(BHT)，产率并无明显 变化，这排除了自由基路径. 作者还合成了 $\mathrm{Cu}$ 与手性 配体的络合物，用 $\mathrm{X}$ 射线单晶衍射确认了络合物结构， 并且络合物直接作催化剂使用也同样具有很好的反应 效果.

该研究团队提出的反应机理如 Scheme 4 所示. $\mathrm{Cu}$

(a)

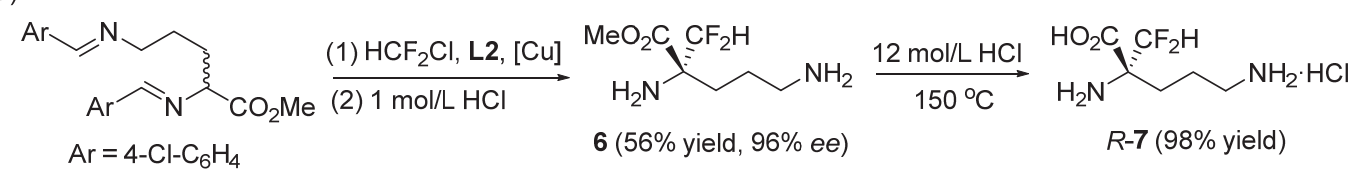
(b)

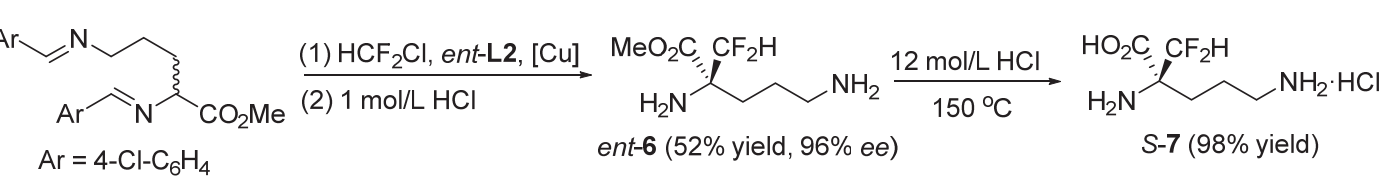

图式 2 不对称合成 $R$-和 $S$-构型的二氟甲基鸟氨酸

Scheme 2 Asymmetric synthesis of $R$ - and $S$-difluoromethylornithines

(a)

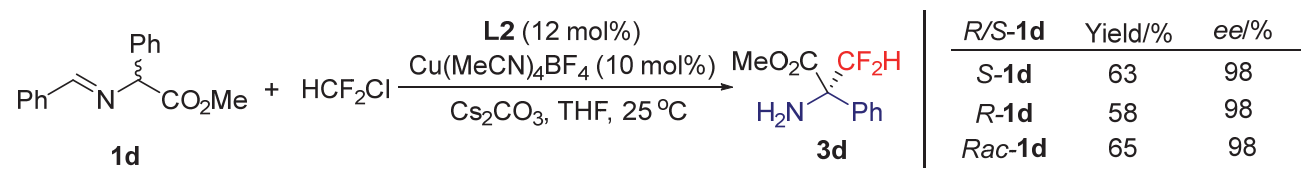

(b)

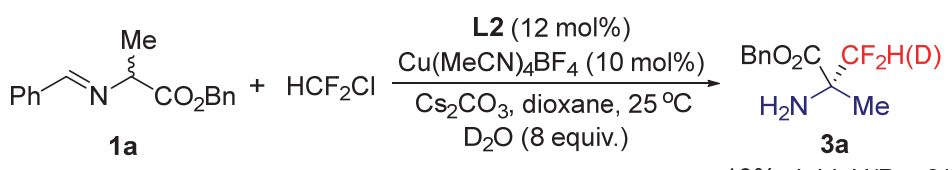

图式 3 机理验证实验

Scheme 3 Experimental evidence

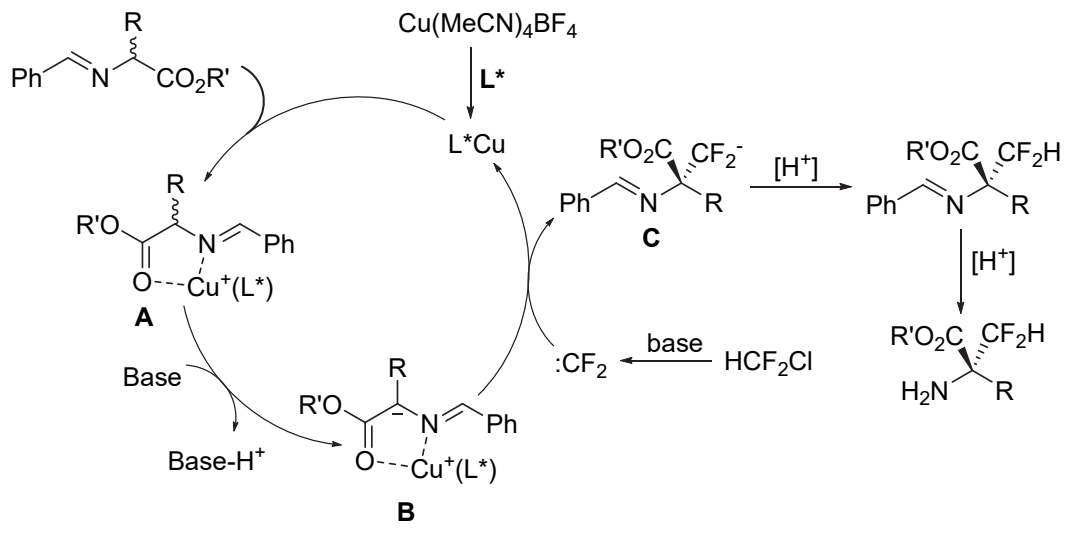

图式 4 可能的反应机理

Scheme 4 Plausible reaction mechanism 
源与手性配体络合后再与底物配位, 得到配合物 A. 配 合物 $\mathbf{A}$ 中酯基 $\alpha$-位 $\mathrm{H}$ 具有一定的酸性，在碳酸铯作用下 中和产生碳负离子 $\mathbf{B}$. 碳负离子容易进攻二氟卡宾, 手 性配体的存在将控制进攻过程的对映选择性. 进攻后产 生中间体 $\mathbf{C}$, 质子化后得到二氟甲基取代产物, 进一步 水解生成手性氨基酸酯.

郭昌课题组首次高效地实现了二氟卡宾对 $\mathrm{C}-\mathrm{H}$ 键 的不对称二氟甲基化, 以优秀的对映选择性构建了二氟 甲基取代的手性季碳中心，反应具有较好的官能团容忍 性, 有望在药物化学研究等领域中发挥重要作用.

\section{References}

[1] Meanwell, N. A. J. Med. Chem. 2018, 61, 5822.

[2] Rong, J.; Ni, C.; Hu, J. Asian J. Org. Chem. 2017, 6, 139.

[3] Birchall, J. M.; Cross, G. W.; Haszeldine, R. N. Proc. Chem. Soc., London 1960, 81.

[4] Ni, C.; Hu, J. Synthesis 2014, 46, 842.

[5] Xie, Q.; Zhu, Z.; Li, L.; Ni, C.; Hu, J. Angew. Chem., Int. Ed. 2019, $58,6405$.

[6] Zhang, X.-Y.; Fu, X.-P.; Zhang, S.; Zhang, X. CCS Chem. 2020, 2, 293.

[7] Iseki, K.; Asada, D.; Takahashi, M.; Nagai, T.; Kobayashi, Y. Tetrahedron: Asymmetry 1996, 7, 1205.

[8] Wang, Y.; Wang, S.; Qiu, P.; Fang, L.; Wang, K.; Zhang, Y.; Zhang, C.; Zhao, T. Org. Biomol. Chem. 2021, 19, 4788.

[9] Peng, L.; Wang, H.; Guo, C. J. Am. Chem. Soc. 2021, 143, 6376.

(Zhao, C.) 